\title{
AVALIAÇÃO DAÁREA DE PRESERVAÇÃO PERMANENTE DO RIO SANTO ANTÔNIO NA COLÔNIA SANTO ANTÔNIO EM GUIA LOPES DA LAGUNA - MS: APLICAÇÃO DO NOVO CÓDIGO FLORESTAL
}

\author{
ASSESSMENT OF SANTO ANTONIO RIVER PERMANENT PRESERVATION \\ AREA AT SANTO ANTONIO COLONY IN GUIA LOPES DA LAGUNA - MATO \\ GROSSO DO SUL STATE: APPLICATION OF THE NEW FORESTRY CODE
}

AVALIACIÓN DEL ÁREA DE PRESERVACIÓN PERMANENTE DEL RIO SANTO ANTONIO EN LA COMUNIDAD SANTO ANTONIO EM LA CIUDAD DE GUIA LOPES DA LAGUNA MS: APLICACIÓN DEL NUEVO CÓDIGO FORESTAL

\author{
Cleiton Messias Rodrigues Abrão - Universidade Federal de Mato Grosso \\ do Sul - Aquidauana - Mato Grosso do Sul - Brasil \\ cleiton.geografo@yahoo.com.br
}

\begin{abstract}
Sidney Kuerten - Universidade Estadual de Mato Grosso do Sul - Jardim - Mato Grosso do Sul - Brasil sidneykuerten@yahoo.com.br
\end{abstract}

\section{Resumo}

0 presente trabalho tem por objetivo analisar a Área de Preservação Permanente (APP) do rio Santo Antônio, no assentamento colônia Santo Antônio frente às mudanças implementadas no chamado código florestal. Foram analisadas três áreas rurais situadas nesse assentamento, sendo consideradas de pequeno e médio tamanho. A área de estudo, bem como as áreas rurais e APP estudadas, foram delimitadas a partir do banco de imagens online no software Quantum GIS com licença de uso gratuita. Entre as imagens disponíveis nesse banco de dados, escolheu-se a do satélite GeoEye 1 de alta resolução espacial $(1,65 \mathrm{~m})$, obtida do complemento open layers plugin Google Earth. Os resultados demonstram que existem graves problemas no cumprimento da legislação florestal. Foram identificadas faixas de APP com ausência de vegetação ciliar e, consequentemente, problemas erosivos, ou sendo usadas para cultivo de pastagem e dessedentação de animais. Ao final, foi proposta a recuperação desses locais, com técnicas de isolamento e recuperação através de plantio de vegetação arbórea nativa ou regeneração natural, bem como a implantação de projetos com a participação dos produtores rurais por meio de Sistemas Agroflorestais (SAFs).

Palavras-chaves: APP, Código Florestal, Desmatamento, Recuperação.

\begin{abstract}
This work aims to analyze the Permanent Preservation Area (PPA) of Santo Antonio River, at Santo Antonio Colony settlement according to the implemented changes in the forestry code. Three rural areas were analyzed in this settlement, they are considered of small and medium size. The study area, as well as studied rural areas and PPA, were delimited from the online images database of Quantum GIS software with free use license. Among available images in this database it was chosen the one from satellite GeoEye 1 of high spatial resolution $(1.65 \mathrm{~m})$, obtained from Google Earth open layers plugin. The results show that there are serious problems for compliance with the forestry legislation. It was identified ranges of PPA with lack of riparian vegetation and therefore erosive problems or being used as pasture and as animal water supply. At the end,
\end{abstract}


it was proposed recovery of these places with restoration and isolation techniques through planting native arboreal vegetation or natural regeneration, as well as implementing projects with the assistance of rural producers through Agroforestry Systems (SAFs).

keywords: PPA, Forestry Code, Deforestation, Recovering.

\section{Resumen}

El presente trabajo tiene como objetivo analizar el Área de Preservación Permanente (APP) del río Santo Antonio en el asentamiento rural de la colonia Santo Antonio frente a las modificaciones implementadas en el llamado código forestal. Fueron analizadas tres áreas rurales situadas en ese asentamiento, siendo consideradas de pequeño y medio tamaño. El área de investigación así como las áreas rurales y APP estudiadas, fueron delimitadas a partir del banco de datos de imágenes en línea del software Quantum GIS con licencia de uso gratuito. Entre las imágenes disponibles en ese banco de datos se escogió la del satélite GeoEye 1 de alta resolución espacial $(1,65 \mathrm{~m})$, obtenida del complemento open layers plugin Google Earth. Los resultados demuestran que existen graves problemas en el cumplimiento de la legislación forestal. Fueron identificadas franjas de APP con ausencia de vegetación ciliar y, consecuentemente problemas erosivos 0 franjas siendo utilizadas para el cultivo de pastos y desedentación de animales. Finalmente se ha propuesto un plan para la recuperación de esos locales con técnicas de aislamiento y recuperación a través del plantío de vegetación arbórea nativa o regeneración natural, así como la implantación de proyectos con la participación de los productores rurales a través de Sistemas Agroforestales.

Palabras clave: APP, Código Forestal, Deforestación, Recuperación.

Introdução

As modificações na paisagem provocadas pelas ações do homem vêm,inevitavelmente, causando desequilíbrios sobre os mais diversos sistemas naturais. O uso da terra para cultivo de variedades agrícolas ou pastagens vem crescendo e muitas dessas atividades são práticas próximas aos cursos d'água. Consequentemente, estas e outras atividades acabam exercendo pressão sobre áreas de vegetação natural e, no caso, é a vegetação ciliar ou ripária que protege os mananciais de água que são fortemente alteradas.

Quando suprimidas aumenta-se a fragilidade dessas áreas, pois sua ausência acarreta o surgimento de processos erosivos, perda de solos agricultáveis, assoreamento de canais e redução da biodiversidade local (Botelho; Silva, 2011). Essas áreas de vegetação próximas aos canais fluviais são legalmente denominadas de Áreas de Preservação Permanente (APPs), cujo marco inicial de sua criação foi o código florestal brasileiro, lei $\mathrm{n}^{\mathrm{o}}$ 4.771/65 (Brasil, 1965).

As APPs são consideradas locais essenciais para o ambiente fluvial, desempenhando funções biológicas como fontes de alimentos para fauna terrestre e aquática e funções hidrológicas contra a erosão marginal, filtro natural de água, proteção contra contaminação por efluentes químicos e cobertura do solo protegendo contra a degradação (Brasil, 1965). 
Nesse sentido, essas áreas são de vital importância para proteger e prevenir desequilíbrios no meio ambiente. No entanto, alguns trabalhos científicos demonstram que há diversas situações de irregularidades entre a preservação da vegetação ciliar e o uso da terra (Cardoso; Aquino, 2013; Coutinho et al., 2013; Pinto; Rossete, 2012).Segundo Görgen (2009), essa situação deve-se também à falta de fiscalização e cobrança pelas autoridades para que essas áreas se mantenham preservadas, principalmente as áreas rurais, que muitas vezes estão localizadas em lugares de difícil acesso.

Recentemente, para reverter essa situação foi promulgada a lei de $\mathrm{n}^{\mathrm{o}}$ 12.651/12 (Brasil, 2012 ${ }^{\mathrm{a}}$ ) que substituiu a lei $\mathrm{n}^{\mathrm{o}}$ 4.771/65 (Brasil, 1965), denominada de novo código florestal. Segundo Valente (2012), essa lei foi aprovada sob forte pressão política de representantes da classe ruralista, que esperavam a dispensa jurídica de averbação da reserva legal, e de ambientalistas, para a recuperação e punição dos crimes florestais cometidos nos últimos 45 anos.

Entretanto, a maior polêmica entre as poucas mudanças feitas no seu conteúdo foi a adoção dos módulos fiscais para a recuperação das APPs, ao definir a faixa de vegetação ciliar a ser recomposta de acordo com a quantidade de módulos fiscais das áreas rurais com APP ripária (Ellovitch; Valera, 2013).

O avanço das geotecnologias e disponibilidade de acesso a softwares e imagens orbitais gratuitas, fomenta a produção de trabalhos na espacialização e identificação de conflitos entre uso da terra e legislação, servindo de base para o planejamento territorial. Nesse contexto, este estudo tem por objetivo avaliar a preservação da APP do rio Santo Antônio, na margem direita deste canal fluvial, sobre áreas rurais situadas no assentamento colônia Santo Antônio, com o uso das geotecnologias disponíveis gratuitamente e discutir o método de recuperação dessas áreas segundo o novo código florestal (Brasil, 2012a).

Existe a carência de estudos sobre essa área justificando a necessidade de pesquisa. Trata-se de manancial de extrema importância para a sociedade local. Segundo dados da Agência Nacional de Águas (2015), $100 \%$ do abastecimento público da cidade de Guia Lopes da Laguna provêm do rio Santo Antônio. Nesta conjuntura, optou-se por estudar o assentamento Colônia Santo Antônio, cuja área está situada próxima ao perímetro urbano e possui fácil acesso. 
O município apresenta outras áreas de assentamentos rurais próximos aos canais fluviais em situação parecida com a área de estudo e que deverão se adequar às regras da nova legislação. Foram propostas soluções de usos sustentáveis que visam aproveitar os recursos naturais disponíveis nessas áreas, de forma a minimizar os impactos com manejo de reflorestamento e sistemas agroflorestais (SAF). Por se tratar de uma área com pequenos produtores rurais assentados esta pode ser uma solução viável, pois torna-se uma prática que promove a geração de renda e conservação dos recursos naturais (Rebeschini, 2010).

Materiais e métodos

Localização da Área de estudo

A área estudada está localizada entre as latitudes $21^{\circ} 26^{\prime} 0^{\prime \prime} \mathrm{S}$ e $21^{\circ} 28^{\prime} 30^{\prime \prime} \mathrm{S}$ e longitudes $56^{\circ} 03^{\prime} 0^{\prime \prime} \mathrm{O}$ e $56^{\circ} 07^{\prime} 00^{\prime \prime} \mathrm{O}$, distante sete quilômetros do centro urbano de Guia Lopes da Laguna, em Mato Grosso do Sul(MS)(Figura 1).Este município está localizado na região sudoeste do estado, pertencente à microrregião da Bodoquena, distante $228 \mathrm{~km}$ de Campo Grande, capital do estado (Mato Grosso do Sul, 2011).

Figura 1 - Localização do assentamento colônia Santo

Antônio no município de Guia Lopes da Laguna

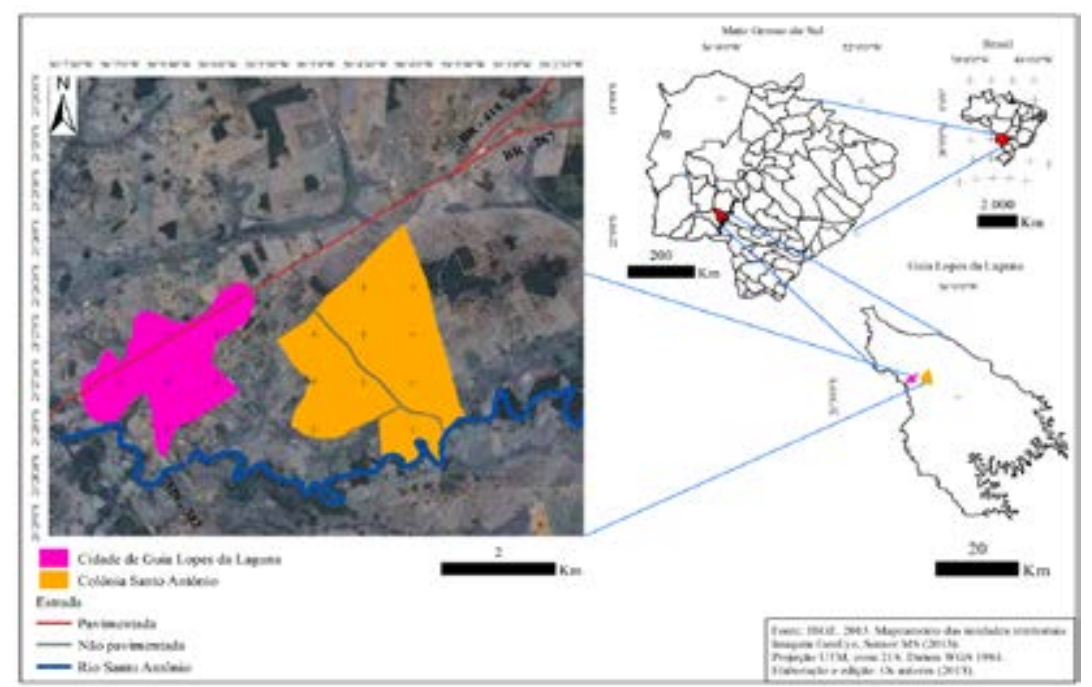


Materiais

- Para a realização da pesquisa utilizou-se os seguintes materiais:

- Imagem de satélite GeoEye 1, sensor MS com resolução espacial de 1,65 m, disponível gratuitamente no software Google Earth, com data de 20/04/2013;

- Software Quantum GIS (QGIS) 1.8.0 versão Lisboa;

- Trena de medida com 50m de extensão;

- Global Positioning System (GPS)- Garmin Etrex.

\section{Métodos}

A pesquisa foi dividida em três etapas: revisão bibliográfica, mapeamento e trabalho de campo. A primeira etapa da pesquisa constituiu-se na realização do embasamento teórico sobre a legislação florestal no Brasil, a importância das APPs para os mananciais e as recentes mudanças no código florestal brasileiro.

Por se tratar de uma área pequena, com pouco mais de $8,5 \mathrm{~km}^{2}$, optou-se por usar imagem disponível do satélite GeoEye-1, sensor MS (Multispectral Sensor)com resolução espacial de 1,65m, extraída do banco de imagens do software Google Earth comdata de 20 de abril de 2013, disponível gratuitamente nocomplemento open layersplugin online do programa Quantum GIS(QGIS) 1.8.0 versão Lisboa. Optou-se por este software pela facilidade de acesso às imagens de alta resolução bem como por possuir licença de uso gratuita. Inicialmente foi delimitada a área de estudo com a criação do arquivo shape file (polígono), seguida pela vetorização do trecho do canal fluvial e as vias de acesso (linha).

Posteriormente a APP do rio Santo Antônio foi vetorizada somente em áreas rurais demarcadas na colônia Santo Antônio, encontradas sobre a margem direita do canal. Após a identificação da área, foram realizados três trabalhos de campo entre os meses de junho, julho e agosto de 2013 para coletar informações de medidas, uso da terra, cobertura vegetal, estado de conservação na APP estudada e coordenadas geográficas em pontos de controle. 


\section{Resultados e discussão}

Foram encontradas APP ao longo do trecho do rio Santo Antonio que cruza o assentamento em apenas três áreas rurais do assentamento (Figura 2). Neste trabalho, optou-se por denominar as áreas rurais da seguinte forma: “Área A”, “Área B” e “ Área C”.

Figura 2 - Áreas rurais da colônia Santo Antônio com APP

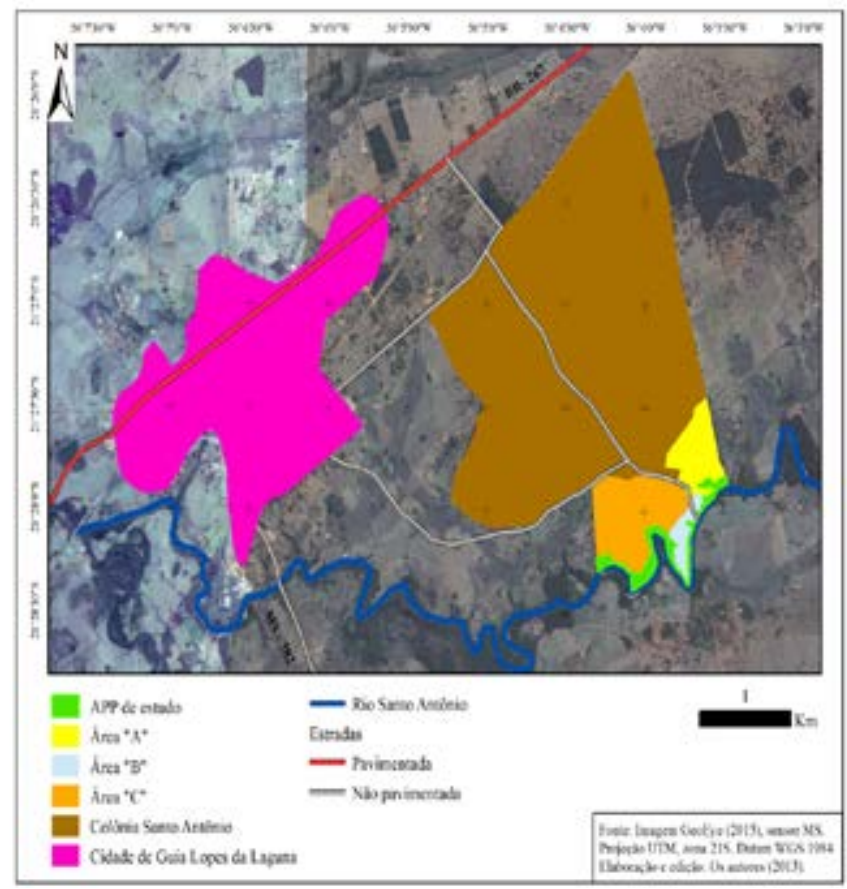

Ao total, a APP presente na colônia Santo Antônio tem por extensão $2,7 \mathrm{~km}$. As três áreas que possuem APP não estão totalmente de acordo com a legislação, apresentando distintos casos de irregularidades e impactos. Dentre os três casos analisados, a área "A" foi a que apresentou maior trecho de APP em bom estado de conservação (Figura 3), entretanto, ela não está cercada corretamente, fato que permite o acesso de animais domésticos no seu interior. 
Figura 3 - Trecho de APP em bom estado de conservação localizado na área " $A$ ". Nota-se a ausência de cerca de arame que deveria estar isolando a faixa de vegetação das demais partes das áreas

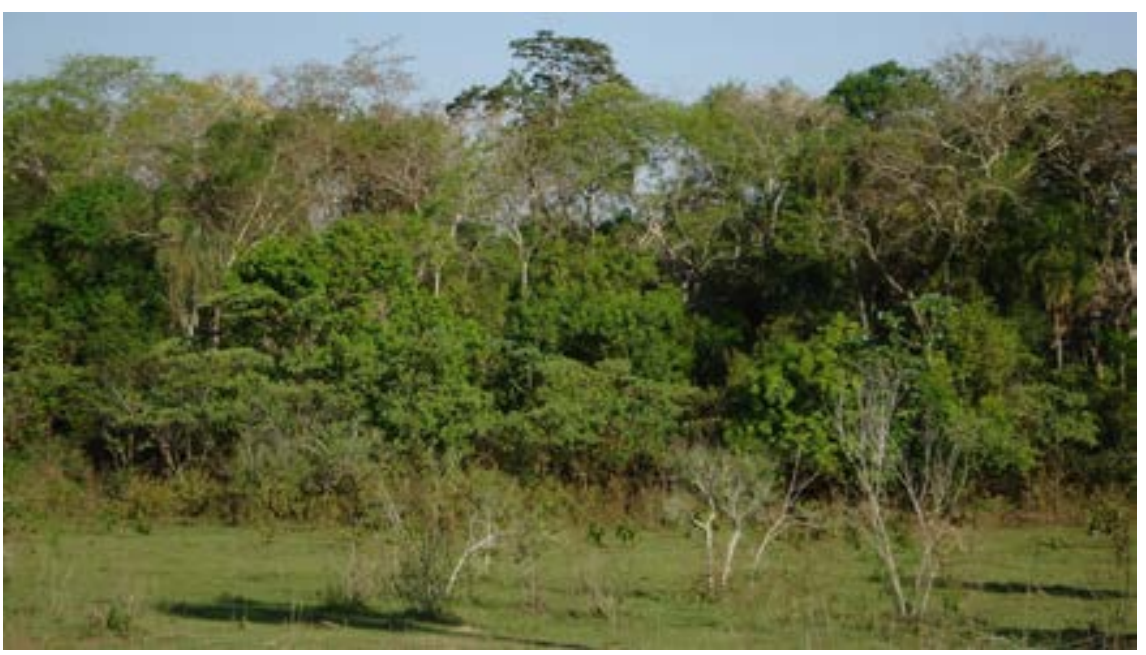

Fonte: Os autores (2013)

Nas áreas B e C,existem situações de danos maiores que estão afetando o canal e prejudicando os recursos naturais. Em pesquisa de campo foram observados quatro impactos principais: problemas de erosão, infestação por gramíneas exóticas, presença de animais domésticos e baixa densidade vegetacional.

A figura 4a apresenta o trecho situado na área "B" com sérios danos causados pela erosão marginal, que está ocorrendo consequentemente pela ausência parcial de vegetação ciliar, visto que parte da vegetação nativa foi removida da área para implantação de pastagem. A implantação de pastagens exóticas como Colonião (Panicum maximum jacq), Braquiária (Brachiaria decumbens) e Braquiarão (Brachiaria brizantha) geram impactos sobre áreas de vegetação ao competir por espaço, luz e nutrientes (Figura 4b).

Na área estudada, elas invadiram grande parte dos locais que deveriam possuir vegetação arbórea e podem ser consideradas ameaçadoras ao equilíbrio ecológico, visto que dificultam a regeneração da vegetação nativa (Martins, 2007). 
Figura 4 -A - Trecho da área de estudo com processos erosivos em estado acelerado localizado na área "B". B -Presença de gramíneas exóticas dentro da APP localizada na área "C"

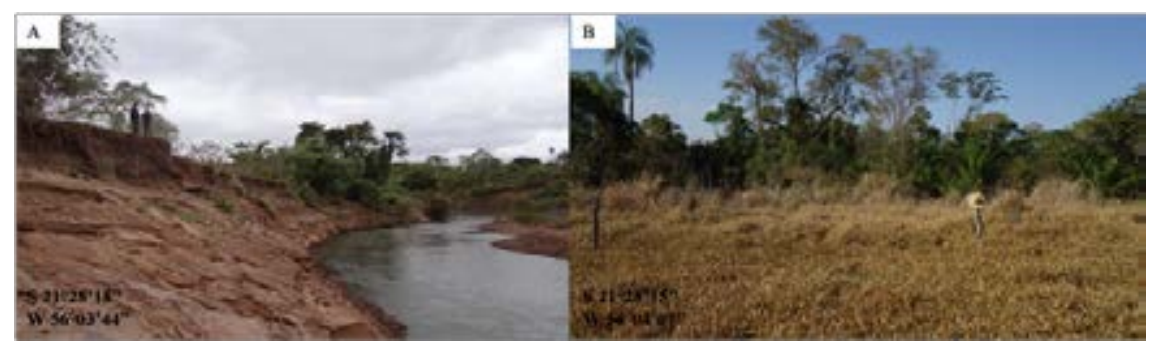

Fonte: Os autores (2013)

Neste contexto, com a presença de gramíneas em alguns trechos de APP, animais domésticos, principalmente bovinos, têm acesso livre à essas área s(Figura 5a) e causam danos à vegetação ciliar. Isto ocorre em virtude da falta de cerca, que deveria isolar a APP corretamente, pois em algumas partes foram encontradas cercas próximas ao canal e não fora da APP, como deveria ocorrer (Figura 5b). Neste caso, a água do rio é usada para dessedentação desses animais e, na maioria das vezes a vegetação é usada como alimento e abrigo no período das chuvas e épocas de inverno rigoroso.

Figura 5 -A - Presença de animais domésticos (bovinos) na APP, localizados na área "B". B - Cerca próxima ao canal, localizada na área "C"

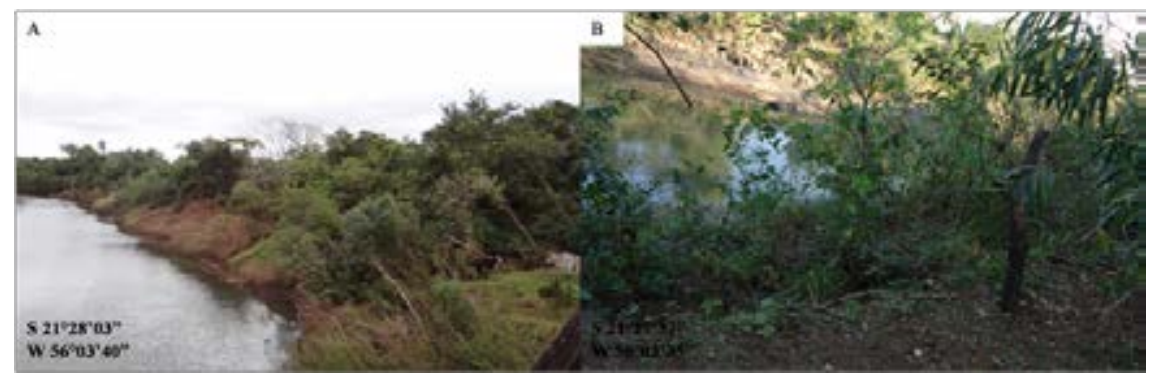

Fonte: Os autores (2013)

Outro problema detectado foram áreas com baixa densidade vegetacional (Figura 6), em pontos onde a dimensão da APP, calculada a partir 
do leito do rio, foi mensurada em apenas $10 \mathrm{~m}$ de comprimento, local cuja largura definida pela legislação deveria ser de $50 \mathrm{~m}$. Nesses mesmos locais, foi possível observar a outra margem do canal (margem esquerda) que também apresenta ausência de vegetação ciliar.

Figura 6 - Faixa de APP com $10 \mathrm{~m}$ de comprimento. Ao fundo, é possível ver a outra margem do canal (esquerda), o que caracteriza o descumprimento da lei e baixa densidade vegetacional, localizada na área "B"

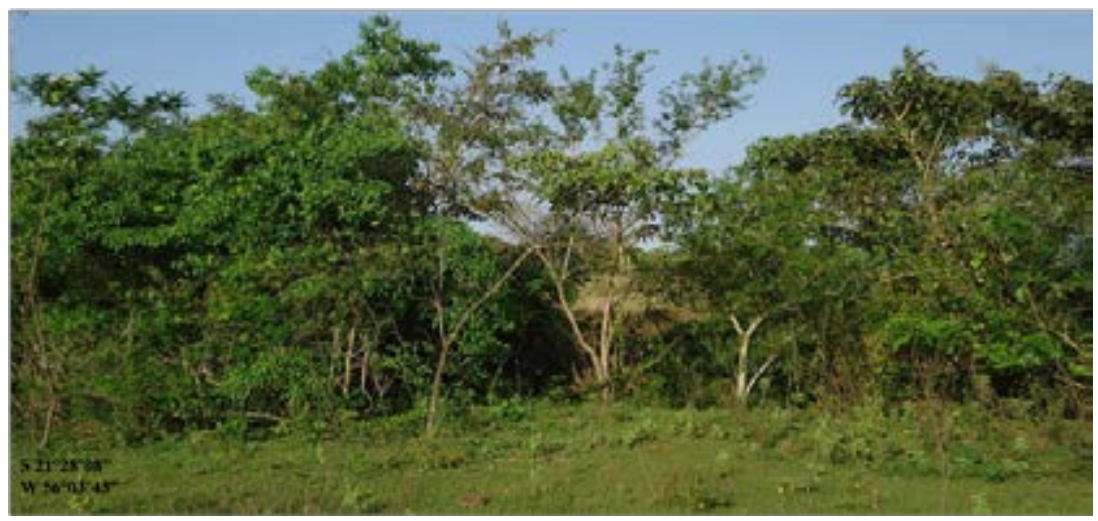

Fonte: Os autores (2013)

\section{Discussão}

\section{Aplicação da nova metodologia para recuperação das APPs ripárias}

A lei $\mathrm{n}^{\circ} 12.727$ (Brasil, 2012b) instituiu a recuperação das APPs por meio da quantidade de módulos fiscais da propriedade rural em que ela esteja localizada, quantidade que indicará o total a ser recuperado. A partir das situações encontradas na APP investigada, as áreas que apresentam irregularidades deverão adequar-se à legislação.

Os módulos fiscais são utilizados para definir o imposto sobre as áreas rurais e o enquadramento de áreas rurais em pequenas, médias e grandes propriedades. Pequenas propriedades, com até 4 módulos fiscais; médias, com área de 5 a 15 módulos fiscais; e grandes, com área superior a 15 módulos fiscais, cuja alteração foi fortemente criticada 
pelos representantes ambientalistas no cenário político nacional (ABC; SPBC, 2011).

Essa medida determina a recuperação de APP's com atividades econômicas consolidadas até julho de 2008. No caso das áreas rurais com APP na colônia Santo Antônio, são consideradas áreas já consolidadas, pois foram ocupadas no início da década de 1970 e, por isso, devem recuperar sua APP conforme os seus respectivos módulos fiscais e recomposição para APP, apresentados abaixo na tabela 1.

Tabela 1 - Tamanho das áreas com APP na colônia Santo Antônio e seu respectivo módulo fiscal

\begin{tabular}{|c|c|c|c|}
\hline Áreas & Tamanho da área (ha) & Módulo fiscal & Recomposição da APP \\
\hline Área "A" & 40 ha & 1 & $5 \mathrm{~m}$ \\
\hline Área "B" & 09 ha & 1 & $5 \mathrm{~m}$ \\
\hline Área "C" & 60 ha & 2 & $8 \mathrm{~m}$ \\
\hline
\end{tabular}

Fonte: Landau et al. (2012)

Um relatório elaborado pela Empresa Brasileira de Pesquisa Agropecuária (EMBRAPA) (Landau et al., 2012) aponta que, na cidade de Guia Lopes da Laguna, um módulo fiscal equivale a 50 hectares (ha) de terra, ou seja, de acordo com o novo código florestal, uma pequena propriedade no município tem entre 50 e 200 ha de área.

De acordo com Valente (2012), essa alteração gerou uma grande diferença no tamanho das APP's a serem recuperadas pelo Brasil, pois uma propriedade localizada na região Norte considerada pequena pelo código florestal pode chegar a ter 400 ha, já uma na região Sul do país pode chegar apenas a 20 ha, ou seja, houve uma grande disparidade nos respectivos tamanhos de APP tanto para a pequena quanto para a grande propriedade rural.

Para retratar as consequências que essa mudança poderá acarretar em uma escala maior, uma pesquisa realizada acerca dos problemas sobre a aplicação dessa metodologia proposta para recuperar as APPs, aponta que 80\% das áreas de vegetação ciliar em rios maiores que $600 \mathrm{~m}$ de largura foram anistiadas, ou seja, estas áreas deverão recuperar no máximo $30 \mathrm{~m}$ de APP, variando ainda de acordo com a quantidade de módulos fiscais das propriedades rurais em que estão localizadas (Valente, 2012). 
Segundo o código florestal anterior (Brasil, 1965), esses mesmos rios deveriam manter preservada, em ambas as margens, uma faixa de APP com 500 m de extensão. Esta situação foi denominada como "efeito escadinha”, pois irá atingir os rios menores (estreitos) até chegar aos maiores (largos). Assim como no rio Santo Antônio e outros cursos d'água médios e pequenos, boa parte será afetada com essa nova regra de recuperação, acarretando o surgimento de impactos.

Para melhor exemplificar essa situação, uma pesquisa citada por Lewinsohon et al. (2010) sobre a fauna da Mata Atlântica, mostra que 50\% de espécies de anuros (sapos e rãs) vivem em locais úmidos, banhados por canais menores de $5 \mathrm{~m}$ de largura. Outros animais como mamíferos semi-aquáticos e aves também utilizam os recursos da floresta como parte da sua cadeia alimentar ou habitat e sofrerão com a falta de disponibilidade de reserva florestal mais ampla para interagir em seus ambientes naturais.

Sendo assim, pode-se observar (Figura 7) o tamanho da APP a ser recomposta em um trecho da APP no rio Santo Antônio. Levando-se em consideração o tamanho da área "B”, na qual está localizado esse trecho de 9 ha e se enquadrando em 1 módulo fiscal (Landau et al., 2012), é possível estabelecer a medida de apenas $5 \mathrm{~m}$ para recuperação da APP degradada.

Figura7 - Área com ausência de APP e que deve ser recuperada na área "B". A vegetação é composta por gramíneas e pequenos arbustos que não oferecem proteção adequada.

Nota-se que a distância entre a primeira pessoa, próxima ao canal, e a segunda, equivale a 5m, ou seja, a área que deverá ser recuperada com vegetação arbórea.

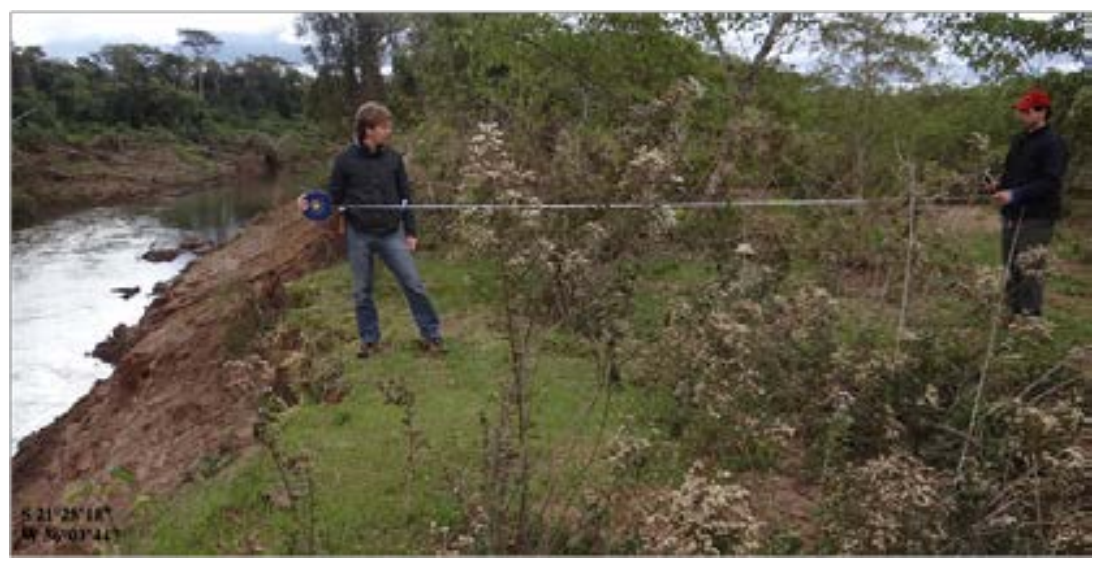

Fonte: Os autores (2013) 
Outro problema que pode ser apontado refere-se à quantidade de espécies arbóreas que poderão ser plantadas nesses locais. Um fator importante nas florestas ripárias que não foi considerado na redação do código florestal (Brasil, 2012) e que, segundo Martins (2007), é recomendado nos projetos de recuperação em áreas degradadas, refere-se a um espaçamento entre as mudas de árvores de no mínimo 2,0 m x 2,0 m de distância.

Com base nessa informação e num cálculo rápido, é possível verificar a diferença da quantidade de árvores que cabem nas duas medidas de APP. $\mathrm{Na}$ faixa de $5 \mathrm{~m}$ podem ser plantadas duas mudas de árvores, enquanto que na medida estabelecida pelo código florestal de 1965, cuja faixa recuperada era de $50 \mathrm{~m}$, poderiam ser plantadas vinte mudas de árvores.

Além disso, em outras áreas adjacentes ao canal com pouca vegetação, a própria dinâmica de enchentes e inundações causa a remoção da vegetação que resta. Assim, danos e fracassos podem acontecer na tentativa de recuperar as áreas, pois a cada inundação que ocorre, naturalmente são transportados sedimentos e materiais da margem para o leito e, dessa forma, as plantas podem ser removidas ou curvadas pela força do fluxo fluvial, necessitando de um novo replantio da área, fato que onera e demanda tempo no projeto de recuperação.

\section{Medidasde recuperação e recomposição para área de estudo}

Em virtude dos problemas encontrados, foram propostas recomendações com técnicas de recuperação que envolvam diversos conhecimentos científicos interdisciplinares para idealizar técnicas e propor modelos de recuperação para cada tipo de área degradada (Kageyama; Gandara, 2009). Para isso, devem ser levados em consideração os aspectos naturais como solo, relevo, hidrologia, fauna, flora, bem como a ocupação e o uso da terra.

No caso de APP's situadas em áreas rurais, os agricultores devem ser os principais envolvidos em planos de recuperação, pois recai sobre eles a responsabilidade por danos florestais e a cobrança legal pela preservação de áreas verdes (Rodrigues; Gandolfi, 2009).

Para que haja sucesso, o projeto de recuperação deve aliar o comprometimento entre produtores rurais e os órgãos públicos de fiscalização, secretarias de meio ambiente, escolas, universidades, grupos de assistência técnica qualificada que, em conjunto, deverão acompanhar todos os processos de elaboração, implantação e manejo do projeto (Kageyama; 
Gandara, 2009). Ainda assim, recai sobre o proprietário o contínuo manejo da área reflorestada até o estágio de estabilidade das plantas, realizando o combate às pragas e proteção contara as intempéries neste período.

Para iniciar um projeto de recuperação, sugere-se a utilização de técnicas de manejos (Tabela 2) propostas por Rodrigues e Gandolfi (2009).

Tabela 2 -Medidas indicadas para recuperar APP degradadas

\begin{tabular}{|c|}
\hline 1 - Isolamento da área. \\
\hline 2 - Eliminação seletiva ou desbaste de espécie que competem com a vegetação natural. \\
\hline 3 - Enriquecimento da vegetação com plantio de árvores novas e raras \\
\hline 4 - Implantação de espécies pioneiras frutíferas em áreas degradadas atrativas à fauna silvestre. \\
\hline
\end{tabular}

Fonte: Adaptado de Rodrigues e Gandolfi (2009)

O isolamento da área consiste no primeiro passo para a recuperação de áreas parcialmente ou totalmente degradadas. No caso da APP estudada, é importante isolar a vegetação ripária por meio de cerca com arame de aço devido à presença de animas domésticos nas áreas com pastagens. Em algumas áreas com uma vegetação ripária em boas condições naturais sem a presença infestante de espécies de gramíneas, só o isolamento pode ser suficiente para sua recuperação, pois a vegetação se regenerará naturalmente por ainda manter a sua resiliência.

Nos locais mais afetados pela presença de espécies competidoras com as plantas nativas, além do isolamento da área, serão necessários manejos como a eliminação de espécies oportunistas como as gramíneas exóticas e um controle das lináceas (cipós), pois estas dificultam a regeneração natural da vegetação (Figura 8). A regeneração natural em áreas ripárias e degradadas é mais barata sob o ponto de vista econômico, porém mais lenta no ponto de vista biológico (Martins, 2007). 
Figura 8 - Vegetação arbórea crescendo junto às gramíneas na área “C”. É necessário o manejo de limpeza ao redor dessas plantas que se regeneram espontaneamente, favorecendo o seu crescimento, ademais, a matéria orgânica da grama protege o solo e conserva a umidade.

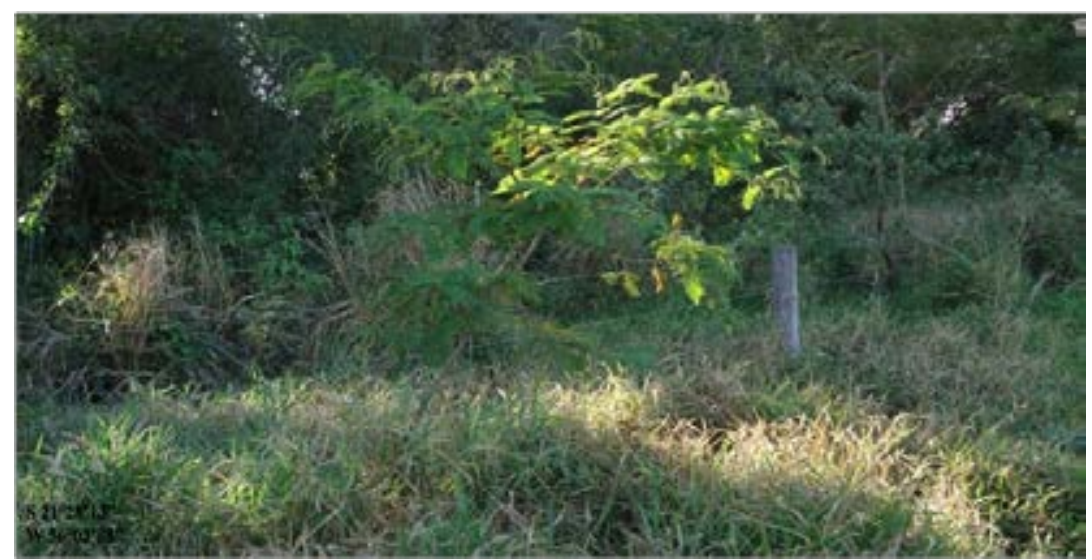

Fonte: Os autores (2013)

Martins (2007) recomenda o coroamento, ou seja, a limpeza ao entorno das mudas, tanto as que nascem naturalmente ou que são plantadas. Esse procedimento, além de fornecer matéria orgânica (biomassa) às gramíneas, poderá proteger o solo e preservar a umidade, favorecendo as mudas. Quando a infestação de gramíneas é alta, recomenda-se o plantio adensado de mudas com espaçamento entre mudas pioneiras e não pioneiras de 1,0 x 1,0 m, o qual proporciona maioriores proteção do solo e inibição do crescimento de gramíneas.

Essa técnica também pode ser utilizada para enriquecer áreas com baixa densidade vegetacional. Segundo Guerra (2012), a manutenção ou recuperação com vegetação arbórea em áreas com solo exposto é um fator que combate a erosão, causada, sobretudo, pelo escoamento superficial ou subsuperficial durante os eventos de precipitação.

As espécies mais recomendadas são as nativas, que podem ser encontradas no próprio lugar, pois já estão adaptadas às condições locais e possuem maior probabilidade de sucesso. Segundo Kageyama e Gandara (2009), o uso de espécies exóticas em APP's pode ser perigoso, pois estas podem ser agressivas ao meio ambiente, causando distúrbios biológicos que poderão afetar todo o sistema. 
No entanto, o código florestal (Brasil, 2012a) permite o plantio de espécies exóticas em $50 \%$ da APP como medida de recuperação e geração de renda. Essa alteração foi mais uma das mudanças criticadas pelos pesquisadores da ABC e SBPC (2011) que, ao invés da recuperação com espécies exóticas, defendem incentivos para a produção sustentável de espécies nativas nas áreas de APP.

Outra maneira de recuperar uma APP ripária é através do SAF, é por meio do plantio de espécies arbóreas nativas com algum valor comercial para produção de lenha, madeira, flores, frutos e mel. Além de permitir a recuperação da APP, o uso de espécies nativas visa beneficiar pequenos produtores e assentamentos, pois possibilita a geração de renda concomitante à preservação, assim como o cultivo diversificado de alimentos para a família e que também podem ser comercializados em feiras e comércio local (Rebeschini, 2010).

Segundo Martins (2007), os SAF's são classificados em silviagrícolas, com o cultivo de espécies arbóreas e culturas agrícolas, silvipastoris, que incluem a prática de cultivo de espécies arbóreo e criação de animais, e agrosilvipastoris, que envolvem o cultivo agrícola e de espécies arbóreas em consórcio com a criação de animais. Os custos de produção são menores, pois são usados menor quantidade de insumos e defensivos, beneficiando diretamente o meio ambiente (Martins, 2007).

Uma instrução normativa do Ministério do Meio Ambiente prevê o licenciamento ambiental para o uso econômico da APP através do SAF, especificamente em áreas de assentamentos rurais implantados pela reforma agrária, como é o caso da colônia Santo Antônio. Para conceder a licença é preciso realizar estudos prévios que levem em conta a flora e fauna local, os resultados indicarão a eficácia do SAF para a preservação e servirão como uma forma de geração de renda aos agricultores (Rebeschini, 2010).

A implantação de projetos de recuperação em áreas degradadas com cultivos de espécies naturais de alto valor econômico também é uma forma de conservação da vegetação nativa dos biomas. O cerrado, caso da área em estudo, vem sofrendo, nos últimos anos, problemas de degradação em áreas ou pastagens abandonadas, acelerando o avanço do processo de arenificação e remoção de APP's nos rios que abastecem grandes centros urbanos e são utilizados para irrigação (Ribeiro et al., 2008).

Na possibilidade de uso múltiplo, Ribeiro et al. (2008) citam como exemplo o cultivo de Cumbaru ou Baru (Dipteryx alata), que em média, 
após 5 anos do plantio, produz frutos para subsistência, comercialização além de alimento para animais e, ao alcançar os 60 anos, fornecerá madeira de boa qualidade para produção de móveis e construção civil. É importante ressaltar que esta exploração é pautada no modo sustentável e que não prejudica o equilíbrio natural, pois assim que uma árvore é derrubada, outra crescerá e preencherá o espaço criado no dossel da floresta, garantido pela resiliência do ambiente (Martins, 2007).

A avaliação destes projetos de recuperação em áreas degradadas vem sendo discutida recentemente, promovendo debates sobre o uso de modelos convencionais e a criação de novos, visando, assim, melhores resultados com menores custos para produtores e empresas. Segundo Martins (2007), por mais bem planejado e elaborado que seja o projeto de recuperação na APP, não é garantida a obtenção de bons resultados, tornando-se necessária a observação dos fatores que demonstrem o seu sucesso.

Martins (2007) menciona como indicativos de recuperação a capacidade de regeneração natural das áreas, a sua resiliência, a proteção do solo, o controle da erosão, a riqueza de espécies arbóreas, a presença de insetos, como abelhas e formigas, além de aves e mamíferos como agentes dispersores de sementes da flora.

Para Rodrigues e Gandolfi (2009), os resultados do projeto devem apontar o sucesso ou não na recuperação ou restauração da floresta ripária, definindo o estado de equilíbrio que pode ser aceito como satisfatório. Os autores alertam para o tamanho e uso alternativo da APP no código florestal, devendo estes pontos serem revisados.

\section{Considerações finais}

A APP da colônia santo Antônio apresenta bom estado de preservação, mas com áreas que necessitam de recuperação e monitoramento em virtude de problemas relacionados aos processos erosivos, à baixa densidade vegetacional e à competição com gramíneas. As mudanças na forma de recuperação de APP previstas no código florestal devem ser revistas, pois como demonstrado neste trabalho, poderão atingir boa parte dos recursos hídricos, prejudicando solos, vegetação, biodiversidade, bem como a sociedade que usufrui dos seus benefícios. 
Foram elencadas diversas técnicas de recuperação que devem ser apresentadas aos moradores do assentamento para serem avaliadas e, caso seja possível, implantadas com a participação dos assentados. Por meio do apoio dos moradores, faz-se necessária a cobrança das autoridades públicas no amparo à assistência técnica e financeira, uma vez que muitos produtores não têm condições financeiras de recuperar suas áreas, cabendo ao poder público apoiá-los financeiramente e com assistência técnica, ou através de convênios com o setor privado.

A outra proposta de recuperação por meio do SAF deve ser analisada com estudos mais detalhados sobre a viabilidade da preservação e geração de renda. A criação de uma cooperativa entre os produtores é uma proposta que poderá contribuir com a sociedade local, gerar renda e proporcionam o uso sustentável dos recursos florestais. A elaboração de projetos deve ter seus objetivos bem definidos, pois devem priorizar a preservação dos recursos hídricos e possibilitar uma forma alternativa de geração de renda aos produtores.

\section{Agradecimentos}

Os autores agradecem aoConselho Nacional de Desenvolvimento Científico e Tecnológico (CNPq) (processo 406998/2012-4) pelo auxílio financeiro no desenvolvimento das atividades de campo correlatas ao desenvolvimento do projeto de pesquisa. Agradecem também às ações de coparticipação do Grupo de Estudos em Fronteira, Turismo, Território e Região (GEOFRONTTER) da UEMS.

\section{Referências}

ABC; SBPC. O Código florestal e a ciência contribuição para o diálogo: Grupo de trabalho Código Florestal. Sociedade Brasileira para o Progresso da Ciência e Academia Brasileira de Ciências; 2011. 131 p.

AGÊNCIA NACIONAL DE ÁGUAS (ANA) http://www2.ana.gov.br/Paginas/ default.aspx>. Acesso em 10 de jun. de 2015.

BOTELHO, R. G. M.; SILVA, A. S. Bacia hidrográfica e qualidade ambiental. In: VITTE, A. C.; GUERRA, A. J. T. Reflexões sobre a geografia física no Brasil. $5^{\mathrm{a}}$ ed. Rio de Janeiro: Bertrand Brasil, 2011. p. 153 - 192.

BRASIL. Lei $\mathrm{n}^{0} 4.771$ de 15 de setembro de 1965. Código florestal brasileiro: promulgado em 15 de setembro de 1965. Revoga o decreto $\mathrm{n}^{\circ}$ 23.793. Brasília. $14 \mathrm{p}$. 
. Lei $\mathrm{n}^{\circ} 12.651$ de 25 de maio de 2012. Código florestal brasileiro: promulgado em 25 de maio de 2012. Revoga a Lei $n^{\circ} 4.771$ de 15 de Setembro de 1965. Brasília, 2012a. 34 p.

. Lei $\mathrm{n}^{\mathrm{O}} 12.727$ de 17 de outubro de 2012. Código florestal brasileiro: promulgada em 17 de outubro de 2012. Lei que revoga a lei 4.771 de 15 de setembro de 1965 e altera e complementa à lei $\mathrm{n}^{0}$ 12.651. Brasília, 2012b. 10 p.

CARDOSO, J. A.; AQUINO, C. M. S. de. Mapeamento dos conflitos de uso das áreas de preservação permanente (APPs) da bacia do riacho do roncador, Timon (MA). Boletim Goiano de Geografia (Online). v. 33, n. 3. p. 477-482, 2013.

COUTINHO, L. M. et al. Uso da terra e Áreas de Preservação Permanente (APP) na Bacia do Rio da Prata, Castelo-ES. Floresta e Ambiente. v. 20, n. 4, p 425-434, 2013.

ELLOVITCH, M. da F.; VALERA, C. A. Manual do novo código florestal. Revista do Ministério público do estado de Minas Gerais, 2013. 78p

GÖRGEN, F. A. S. O código Florestal: uma oportunidade para agricultura camponesa. Revista Recopa, Junho de 2009 p. 3 e 4.

GUERRA, A. J. T. Processos Erosivos nas Encostas In: GUERRA, A. J. T.; CUNHA, S. B da. Geomorfologia:uma atualização de bases e conceitos $.11^{\mathrm{a}}$ ed. Rio de janeiro: Bertrand Brasil, 2012. p. 149 - 209.

IBGE. Mapeamento das unidades territoriais, 2013.

KAGEYAMA, P.; GANDARA, F. B. Recuperação de Áreas Ciliares In: RODRIGUES, R. R.; LEITÃO - FILHO, H. de F.(Org.). Matas ciliares: conservação e recuperação. $2^{\mathrm{a}}$ ed, $2^{\mathrm{a}}$ reimpressão. São Paulo: Fapesp, 2009. Pag. 249 - 269.

LANDAU, E. C. et al. Variação geográfica do tamanho dos módulos fiscais no Brasil. Sete Lagoas: Editora da EMBRAPA, 2012. 200 p.

LEWINSOHN, T. M. et al. Impactos potenciais das alterações proposta para o código florestal brasileiro na biodiversidade e nos serviços ecossistêmicos. Programa BIOTA/FAPESP. São Paulo, 2010. 12p.

MARTINS, S. V. Recuperação de Matas ciliares. 2a ed. Viçosa, MG: CPT, 2007. 255p.

MATO GROSSO DO SUL. Secretaria de Estado de Meio Ambiente do Planejamento, da Ciência e Tecnologia. - Caderno geoambiental: região Sudoeste. 2011.p. 241-283.

PINTO, C. E. T.; ROSSETE, A. N. Mapeamento dos conflitos no uso da terra em Áreas de Preservação Permanente na microbacia hidrográfica do córrego Capitão Décio, Nova Xavantina - MT. Ciência e Natureza. v. 34, n. 2. p. 139-155, 2012.

REBESCHINI, A. A. Projeto de recuperação e conservação ambiental através do desenvolvimento agroflorestal em comunidades e assentamentos no vale do ribeira e pontal do Paranapanema estado de São Paulo. Revista PROTER. Registro, SP. n. 2, 64 p. Mar. 2010. 
RIBEIRO, J. F. et al. Usos Múltiplos da biodiversidade no bioma do cerrado: estratégias sustentáveis para a sociedade, o agronegócio e os recursos naturais. In: FALEIRO, F. G.; NETO, A. L de F. Savanas: desafios e estratégias para o equilíbrio entre sociedade, agronegócio e recursos naturais. Planaltina, DF. Embrapa Cerrado, 2008. p. 337 - 360.

RODRIGUES, R. R.; GANDOLFI, S. Conceitos, tendências e ações para a recuperação de florestas ciliares In: RODRIGUES, R R.; LEITÃO - FILHO, H. de F.(Org.). Matas ciliares: conservação e recuperação. $2^{\mathrm{a}}$ ed, $2^{\mathrm{a}}$ reimpressão. São Paulo: Fapesp, 2009. p. 235 - 247.

VALENTE, I. Código florestal: os riscos para o meio ambiente e biodiversidade brasileira. Brasília, 2012.24p. Disponível em: <http://www.florestafazadiferenca. org.br/o-futuro-das-florestas/> Acesso em 20 out. 2013.

Cleiton Messias Rodrigues Abrão - Possui Graduação em geografia pela Universidade Estadual de Mato Grosso do Sul. Atualmente é estudante de mestrado em Geografia pela Universidade Federal de Mato Grosso do Sul.

Sidney Kuerten - Possui graduação em Geografia pela Faculdade Estadual de Ciências e Letras de Campo Mourão. Mestrado em Geografia pela Universidade Estadual de Maringá e doutorado em Geociências e Meio Ambiente pela Universidade Estadual Paulista. Atualmente é professor Adjunto IV na Universidade Estadual de Mato Grosso do Sul.

Recebido para publicação em 13 de Abril de 2016 Aceito para publicação em 25 de maio de 2016 